
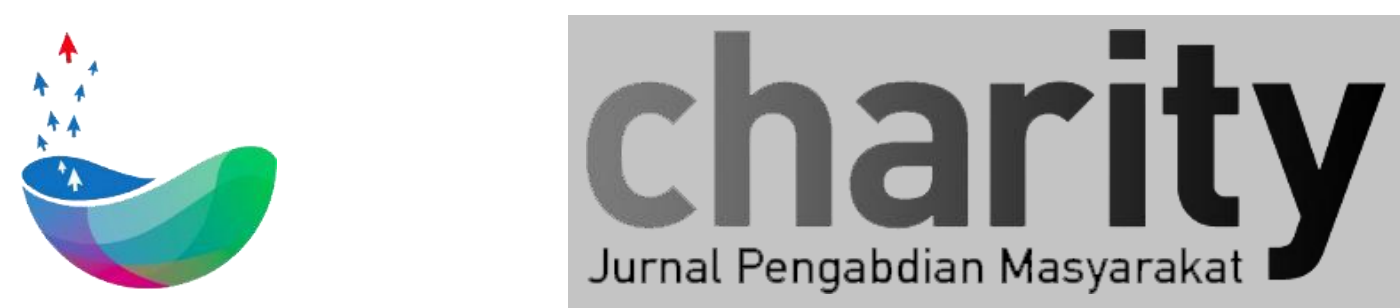

\title{
Perancangan dan Pembuatan Aplikasi Ketahanan Pangan pada Masa Pandemi Covid-19 Berbasis Android di Desa Sukapura
}

\author{
Rd. Rohmat Saedudin ${ }^{1}$, Avon Budiono ${ }^{2}$, Edi Sutoyo ${ }^{3}$, Siti Hajar Komariah ${ }^{4}$, Wawan Tripiawan ${ }^{5}$, Umar Yunan ${ }^{6}$ \\ M. Teguh Kurniawan ${ }^{7}$, R. Yunendah Nur Fuadah ${ }^{8}$, Rahmiati Aulia ${ }^{9}$
}

${ }^{1}$ Desain Komunikasi Visual, Fakultas Rekayasa Industri, Universitas Telkom.

${ }^{2}$ Desain Komunikasi Visual, Fakultas Rekayasa Industri, Universitas Telkom.

${ }^{3}$ Desain Komunikasi Visual, Fakultas Rekayasa Industri, Universitas Telkom.

${ }^{4}$ Desain Komunikasi Visual, Fakultas Industri Kreatif, Universitas Telkom.

Desain Komunikasi Visual, Fakultas Rekayasa Industri, Universitas Telkom.

${ }^{6}$ Desain Komunikasi Visual, Fakultas Rekayasa Industri, Universitas Telkom.

Desain Komunikasi Visual Fakultas Rekayasa Industri, Universitas Telkom.

Desain Komunikasi Visual Fakultas Teknik Elektro, Universitas Telkom.

${ }^{9}$ Desain Komunikasi Visual, Fakultas Industri Kreatif, Universitas Telkom

* \{rdrohmat, avon,edi,sitihajar, wawan, teguh,yunendah, rahmiati\}@telkomuniversity.ac.id;

\section{INFO ARTIKEL}

Diterima 29 Desember 2020

Direvisi 17 Februari 2021

Disetujui 28 Agustus 2021

Tersedia Online 31 Agustus 2021

Keyword: Ketahanan Pangan, Proses Bisnis KerjasamaTripatrit, Aplikasi Berbasis Android.

\begin{abstract}
ABSTRAK
Desa Sukapura dengan potensi yang ada sekarang ini, yaitu Warung kurang lebih 500 warung termasuk (warteg dan warung makan). Jumlah penduduk asli sekitar 11.370 penduduk, pendatang/mahasiswa lebih dari 10rb sehingga potensi jumlah warga yang ada di Desa Sukapura sekitar 25 ribu orang. Berdasarkan data 2018, rata-rata kebutuhan makan warga Desa Sukapura sebesar Rp 25.000/ jiwa/ hari. Sehingga dengan estimasi kasar saja keperluan makan/ pangan warga sukapura adalah 625 juta rupiah per hari atau sekitar 225 milyar rupiah per tahun.
\end{abstract}

Sebagaimana umumnya desa-desa di wilayah Kabupaten Bandung, Desa Sukapura dalam 3 bulan terakhir tidak terlepas dari dampak pandemi covid-19. Nilai potensi dan perputaran ekonomi di bidang pangan yang cukup besar ini di Desa Sukapura, dalam 3 bulan terakhir secara signifikan terdampak oleh kebijakan PSBB, social distance, stay at home, akibat pandemic covid-19. Warga desa banyak yang kehilangan penghasilan, daya beli menurun, kekurangan pasokan dan stok pangan, roda usaha mikro, kecil, dan menengah seperti warung turun drastis omsetnya sampai hanya tinggal 30-40\% saja.

Banyak program yang sudah digulirkan oleh pemerintahan Desa Sukapura baik program mandiri maupun dalam rangka mendukung program pemerintahan di atasnya khususnya terkait penganggulangan penyebaran pandemi covid-19 dan mengatasi dampak yang ditimbulkannya dan dirasakan oleh warga.

Salah satu hal utama yang mendapat perhatian pemerintah, selain pencegahan dan pengetatan penyebaran wabah Covid-19 ini adalah terkait Ketahanan Pangan warga nya dalam kondisi pandemi yang sedang berlangsung berkepanjangan. Untuk mencukupi ketersediaan dan kecukupan stok pangan dengan harga murah terjangkau, pihak Desa menggandeng pihak ke-3, yaitu PT Satoe Juara untuk menyediakan dan memenuhi kebutuhan warga akan sembako murah (beras, minyak goreng, gula, garam, telor, dll). Permasalahan supplier dan stok bahan baku murah bisa diatasi, timbul permasalahan baru mengingat daya beli masyarakat turun, pola distribusi dan penjualan tidak bisa konvensional sebebas dan seperti biasa di tengah kebijakan-kebijakan pencegahan pandemic covid-19. 
Perlu di desain proses bisnis Kerjasama tripatrit dalam rangka mensukseskan program ketahanan pangan ini, yaitu pemerintahan (dalam hal ini Pemerintahan Desa Sukapura), Supplier Sembako Murah, UMKM (para pemilik warung) untuk distribusi sembako murah, dan warga sebagai konsumen dan pengguna sembako.

Bagaimana caranya, program keekonomian rakyat seperti ini dapat berjalan di tengah kebijakan pembatasan social berskala besar (PSBB), social distance dan stay at home sebagai akibat pandemi Covid-19 dengan menggalakan perekonomian berbasis transaksi online dan delivery order. Hal ini demi menjaga jarak sosial dan mentaati kewajiban tinggal dirumah untuk mencegah, membatasi dan menghentikan penyebaran Covid-19.

Program aplikasi ketahanan pangan perlu di rancang bangun dan dibuat untuk menghubungkan konsumen ke penyedia pangan melalui pemesanan online ke agen terdekat dengan memanfaatkan jasa delivery oleh pihak kurir jasa pengantar makanan

\author{
Korespondensi: \\ Direktorat Penelitian dan Pengabdian Masyarakat, Universitas Telkom \\ Jl. Telekomunikasi No. 1, Terusan Buah Batu, Bandung, 40257 Indonesia. \\ E-mail : ppm@telkomuniversity.ac.id \\ ORCID ID: \\ Penulis Pertama: Rd. Rohmat Saedudin \\ https://orcid.org/0000-0001-6914-9514 \\ https://doi.org/10.25124/charity.v4i2 \\ Paper_reg_number xxx @ The Authors. Published by Directorate of Research and Community Service, Telkom \\ University. \\ This is an open access article under the $\mathrm{xxx}$ license (https://creativecommons.org/licenses/xxx)
}

\title{
1. Pendahuluan
}

Desa Sukapura beralamat di jl. Sukapura no. 54 - kodepos 40267, Kecamatan Dayeuhkolot Kabupaten Bandung. Desa Sukapura adalah merupakan daerah yang berbatasan langsung dengan Kawasan Pendidikan Telkom. Penduduk Desa Sukapura berjumlah sekitar 11.370 jiwa.

Jumlah penduduk ini, diluar penduduk nonpermanen yaitu mahasiswa Universitas Telkom yang tinggal di wilayah Desa Sukapura yang jumlahnya mencapai lebih dari 10.000 Mahasiswa. Jumlah warga desa sukapura yang sangat besar ini menjadi tantangan tersendiri bagi pemerintah desa Sukapura untuk memberikan layanan terbaik, dimana diperlukan program-program yang tepat sasaran dan bermanfaat bagi kesejahteraan warganya (Sukapura D., 2020).

Sebagaimana umumnya desa-desa di wilayah Kabupaten Bandung, Desa Sukapura dalam 3 bulan terakhir tidak terlepas dari dampak pandemi covid-19. Kebijakan PSBB, Social Distance, dan stay at home, berakibat banyak pada perekonomian warga khsususnya ketersediaan dan kecukupan pangan warga dan daya beli warga. Banyak program yang sudah digulirkan oleh pemerintahan Desa Sukapura baik program mandiri maupun dalam rangka mendukung program pemerintahan di atasnya khususnya terkait penganggulangan penyebaran pandemi covid-19 dan mengatasi dampak yang ditimbulkannya dan dirasakan oleh warga. 
Salah satu hal utama yang mendapat perhatian pemerintah, selain pencegahan dan pengetatan penyebaran wabah Covid-19 ini adalah terkait Ketahanan Pangan warga nya dalam kondisi pandemi yang sedang berlangsung berkepanjangan.

Salah satu program ketahan pangan tersebut adalah dengan menggandeng Desa, BUMDES, UKM, dan warga untuk tetap bertahan dalam masa pandemi terutama dalam memenuhi kebutuhan hidup/ pangan sehari-hari. Segala upaya di laksanakan, bagaimanapun caranya, kebutuhan pangan warga tetap terpenuhi dengan harga murah dan terjangkau dan ketersediaannya tetap bisa di jaga dan dipenuhi.

Bagaimana caranya, program keekonomian rakyat seperti ini dapat berjalan di tengah kebijakan pembatasan social berskala besar (PSBB), social distance dan stay at home sebagai akibat pandemi Covid-19 dengan menggalakan perekonomian berbasis transaksi online dan delivery order. Hal ini demi menjaga jarak sosial dan mentaati kewajiban tinggal dirumah untuk mencegah, membatasi dan menghentikan penyebaran Covid-19.

Adanya perubahan paradigma, belanja ke tetangga, belanja online, delivery order dan transak-transaksi lainnya yang semula dilakukan secara konvensional menjadi berbasis online, memerlukan dikembangkannya aplikasi interface anatara para pelaku ekonomi kerakyatan dengan mesin/ perangkat cerdas demi mensukseskan program ketahanan pangan warga (Sukapura B. D., 2020).

Program aplikasi ketahanan pangan perlu di rancang bangun dan dibuat untuk menghubungkan konsumen ke penyedia pangan melalui pemesanan online ke agen terdekat dengan memanfaatkan jasa delivery oleh pihak kurir jasa pengantar makanan.

\section{Solusi dan Target Luaran}

\subsection{Solusi yang ditawarkan}

Dari uraian permasalahan yang dihadapi oleh warga Desa Sukapura pada masa pandemic covid-19 ini, setidaknya ada 3 permasalahan utama, yaitu:

1. Bagaimana membangun ketahanan pangan warga

2. Bagaimana meningkatkan daya beli warga yang sedang terpuruk akibat banyak warga yang kehilangan mata pencaharian dan penghasilan

3. Bagaimana roda perekonomian dan transaksi bisa terus berjalan tanpa melangar kebijakan pemerintah yaitu PSBB, social distance dan stay at home.

Untuk mengatasi 3 permasalahan utama di atas, program pengabdian masyarakat skema kolaborasi ini diusulkan dengan menawarkan solusi dari permasalahan warga tersebut, yaitu:

1. Perlu didesain dan dibuat proses bisnis pola Kerjasama tripatrit antara pemerintahan Desa Sukapura, Supplier (PT. Satoe Juara), dan UMKM (Para pemilik warung di Desa Sukapura), untuk membangun sinergi yang saling membawa manfaat bagi semua pihak dengan mengedepankan aspek manfaat bagi warga desa Sukapura khususnya dalam memenuhi kriteria Ketahanan Pangan warga.

2. Perlu dilakukan pemberdayaan sebagian warga yang terdampak langsung oleh pandemi Covid-19 sehingga kehilangan penghasilan, agar dilibatkan dalam program-program padat karya dan kerja jasa lainnya dengan tetap mensukseskan 
program Ketahanan Pangan dengan tetap tidak melanggar kebijakan penanganan dan pencegahan penyebaran pandemic Covid-19

3. Perlu dirancang bangun dan dibuat program alikasi berbasis android, untuk menjadi interface dan penghubung transaksi online antara Tripatrit sebagai penyelenggara dengan warga sebagai konsumen untuk mensukseskan program ketahanan pangan dengan tetap mempertahankan zero Covid-19 di Desa Sukapura (Sukapura B. D., 2020).

\subsection{Target Luaran Kegiatan PPM}

Pada program pengabdian masyarakat ini target luarannya adalah:

1. Menghasilkan Publikasi Ilmiah/ Umum

2. Menghasilkan Barang/ Produk berupa:

1) Menghasilkan Desain Proses Bisnis Kerjasama Tripatrit Program Ketahanan Pangan Desa Sukapura

2) Menghasilkan Mockup dan aplikasi ketahanan pangan berbasis android untuk implementasi Program Kerjasama Tripatrit dalam rangka mensukseskan ketahanan pangan dan menggerakan Kembali roda perekonomian kerakyatan warga Desa Sukapura.

3) Uji Implementasi aplikasi dengan 20 User Pengguna (20 UMKM yang terlibat).

3. Memberikan pelatihan kepada pihak Mitra berupa: pelatihan penggunaan dan simulasi aplikasi ketahanan pangan berbasis android (Pria Utama, 2016).

\section{Metode Pelaksanaan}

Pelaksanaan kegiatan ini direncanakan pada bulan Juli-November 2020 berlokasi di Desa Sukapura Kecamatan Dayeuh Kolot Kabupaten Bandung. Ada 4 Kegiatan inti PPM kolaborasi internal yang akan dilaksanakan pada periode II 2020 ini, yaitu berupa:

1) Perancangan dan pembuatan proses bisnis pola Kerjasama tripatrit antara pemerintahan Desa Sukapura, Supplier (PT. Satoe Juara), dan UMKM (Para pemilik warung di Desa Sukapura), untuk membangun sinergi yang saling membawa manfaat bagi semua pihak dengan mengedepankan aspek manfaat bagi warga desa Sukapura khususnya dalam memenuhi kriteria Ketahanan Pangan warga.

2) Pemberdayaan sebagian warga yang terdampak langsung oleh pandemi Covid-19 sehingga kehilangan penghasilan, agar dilibatkan dalam program-program padat karya dan kerja jasa lainnya dengan tetap mensukseskan program Ketahanan Pangan dengan tetap tidak melanggar kebijakan penanganan dan pencegahan penyebaran pandemic Covid-19

3) Rancang bangun dan Pembuatan Program Alikasi Ketahanan Pangan Berbasis Android, untuk menjadi interface dan penghubung transaksi online antara Tripatrit sebagai penyelenggara dengan warga sebagai konsumen untuk mensukseskan program ketahanan pangan dengan tetap mempertahankan zero Covid-19 di Desa Sukapura.

4) Pelatihan dan simulasi implementasi aplikasi ketahanan pangan berbsis android untuk 20-30 UMKM.

Adapun tahapan pelaksanaan program pengabdian masyarakat kolabirasi ini dilaksanakan dalam 5 tahap, yaitu:

1. Persiapan

Pada tahap ini kegiatan yang akan dilakukan yaitu:

a. Wawancara dan survey ke lokasi mitra secra offline dan online untuk menggali informasi terkait peluang kegiatan pengabdian yang diperlukan disinergikan dengan program Desa Sukapura yang sedang atau akan dijalankan. 
b. Pembuatan Proposal lengkap dengan kesediaan Mitra yang sudah ditentukan di awal berdasarkan hasil survey, yaitu Kepala Desa Sukapura. Kepala Desa akan memfasilitasi pertemuan tripatrit antara Pemerintahan Desa, PT Satoe Juara, dan UMKM di Desa Sukapura.

c. Penyelesaian administrasi dan perijinan lokasi pengabdian Masyarakat

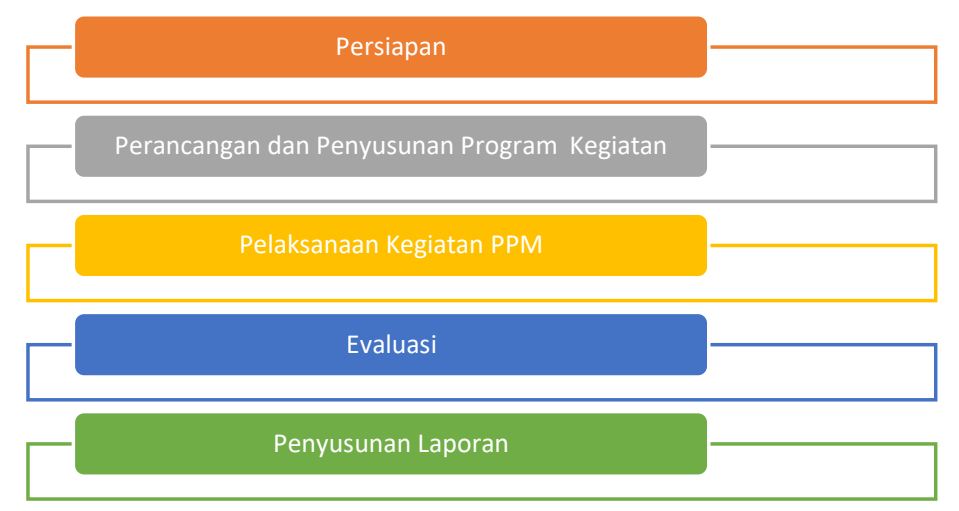

Gambar 1. Tahapan Pelaksanaan Pengabdian Masyarakat

2. Penyusunan program pengabdian

Pada tahap ini, tim menyusun dan membuat program kegiatan terkait Program Ketahanan Pangan warga Desa Sukapura di tengah masa Pandemi Covid-19, berupa pembuatan proses bisnis kerjasama tripatrit, pemberdayaan warga yang terdampak langsung, pembuatan aplikasi berbasis android, dan Pelatihan dan simulasi implementasi aplikasi dengan 20-30 user

3. Pelaksanaan kegiatan

Sub tahap pertama pelaksanaan kegiatan dilakuakan selama 4 bualan efektif mulai dari perancangan proses bisnis secara detil, pembuatan mockup untuk desain tampilan dan proses, serta pembuatan program dan coding aplikasi Ketahanan Pangan berbasis Android. Sub Tahap kedua berupa Pelatihan dan simulasi implementasi aplikasi dengan 20-30 user.

4. Evaluasi

Tahap evaluasi ini bertujuan untuk melihat sejauh mana pencapaian pelaksanaan program pengabdian masyarakat ini terealisasi sesuai dengan rancangan awal. Akan diidentifikasi juga kendala yang ada selama dalam persiapan dan pelaksanaan serta cara penanganannya. Hasil evaluasi akan dijadikan dasar perbaikan dan pengembangan program PPM ke depannya supaya lebih tepat sasaran dan benar-benar membawa dampak yang signifikan bagi masyarakat mitra.

5. Penyusunan Laporan

Penyusunan laporan akhir dilakukan setelah pelaksanaan kegiatan yang merangkum segala aktifitas dan kegiatan dari mulai tahap persiapan sampai evaluasi. 


\section{Hasil Pelaksanaan Kegiatan}

4.1. Perancangan dan pembuatan proses bisnis pola Kerjasama tripatrit antara pemerintahan Desa Sukapura, Supplier (PT. Satoe Juara), dan UMKM (Para pemilik warung di Desa Sukapura), di tambah dengan peran Lembaga keuangan PT Duha Madani Sariah

Proses bisnis Kerjasama dirancang, diinisiasi dan di kukuhkan pada periode awal pelaksanaan PPM, yaitu Juli-Agustus. Dan proses peresmian dan penandatangannya di laksanakan pada bulan Oktober bersamaan dengan peluncuran Warung SeMur/ UMKM dan aplikasi SeMur (Sembako Murah) yang didevelop kemudian menjadi aplikasi Ketahanan Pangan.
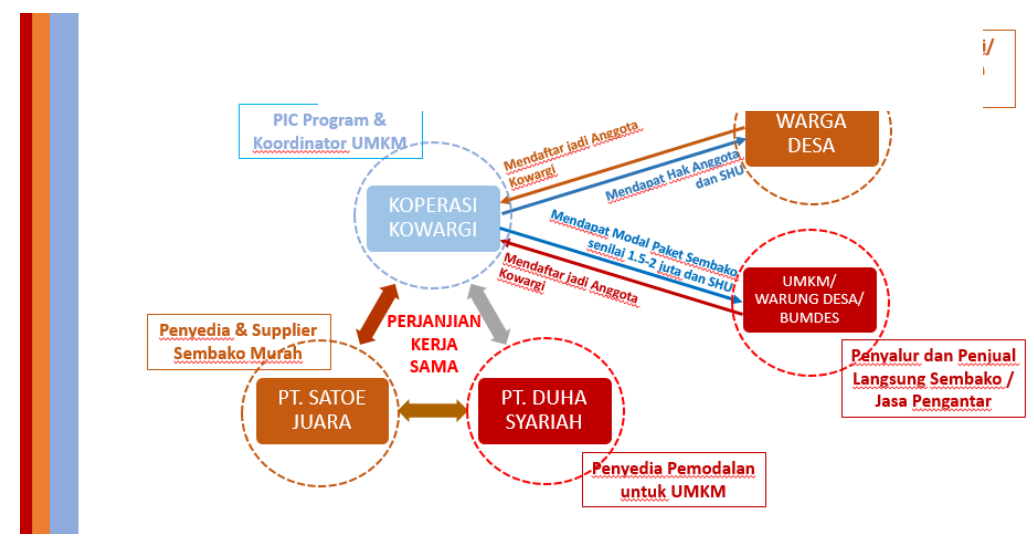

Gambar 2. Pelaksanaan Program PPM: Proses Bisnis Kerjasama Antara Desa Sukapura, Dayeuh Kolot, UMKM Setempat, PT Satoe Juara, dan PT. Duha Syariah

4.2 Pemberdayaan Pandemic warga yang terdampak langsung oleh Pandemic Covid-19 sehingga kehilangan penghasilan, agar dilibatkan dalam program-program padat karya dan kerja jasa lainnya.

Masyarakat Desa Sukapura dan Dayeuh kolot beserta UMKM nya dilibatkan untuk tergabung dalam koperasi KOWARGI SEJAHTERA. Dalam pelaksanaan kegiatan Tim PPM Tel-U mendampingi proses perancangan dan pembentukan koperasi KOWARGI Bersama-sama dengan warga dan BUMDES dari kedua desa. Masyarakat juga boleh terlibat sebagai jasa kurir pengantar produk UMKM kepada warga/ pembeli yang melakukan transaksi pembelian ke warung SeMur mitra koperasi KOWARGI.

4.3 Rancang bangun dan Pembuatan Program Alikasi Ketahanan Pangan Berbasis Android, untuk menjadi interface dan penghubung transaksi online antara Tripatrit sebagai penyelenggara dengan warga sebagai konsumen untuk mensukseskan program ketahanan pangan dengan tetap mempertahankan zero Covid-19 di Desa Sukapura. 
Tim ppm Tel U, melaksaksanakan kegiatan ranvang bangun dan implementasi aplikasi SeMur 4.0 yang sudah dikembangkan menjadi aplikasi Ketahanan Pangan (Aplikasi Ketapang). Proses bisnis dari aplikasi tersebut dapat dilihat pada Gambar 3.

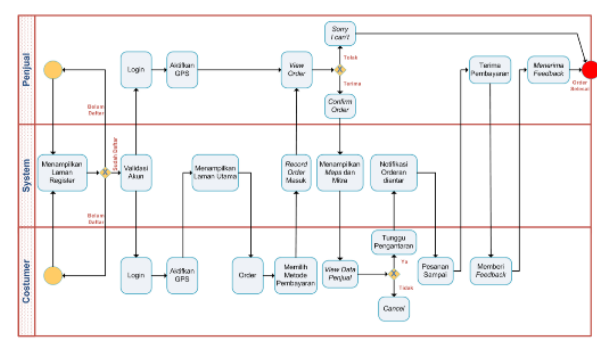

(a)

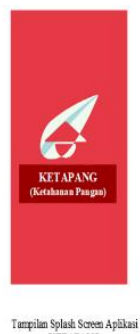

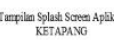

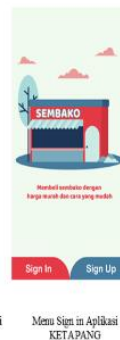

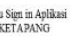

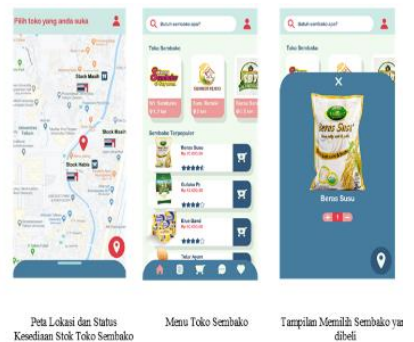

(b)

Gambar 3. Alus Proses (a) dan TampilanAplikasi Ketapang (b)

\subsection{Pelatihan dan simulasi implementasi aplikasi ketahanan pangan berbsis android untuk 20-30 UMKM}

Dalam proses implementasi transaksi jual beli secara online dengan dukungan aplikasi Ketapang, perlu dilaksanakan sosialisasi kepada para user/ pengguna aplikasi yang terlibat, yaitu UMKM, Warga/Anggota Bumdes/ Anggota Koperasi yang mendaftar menjadi jasa kurir dan Warga/ Konsumen sebagai pembeli/ pengorder produk.

Sosialisasi dilaksanakan secara offline dengan tetap memperhatikan protocol Kesehatan di aula Desa Dayeuh Kolot. Pelaksanaan pelatihan dan sosialisasi berlangsung dibagi dalam 2 sesi pagi-siang dan siang-sore.

Pelaksanaan kegiatan berjalan lancar dan sesuai dengan rencana awal kegiatan. Adapun detil penilaian dan harapan mitra atas kegiatan pengabdian masyarakat yang sudah dilaksanakan oleh tim kolaborasi FRI, FTE dan FIK Universitas Telkom, dapat dilihat pada hasil rekapitulasi fedd back dari mitra sasar di Tabel 1 .

Tabel 1. Hasil Rekapitulasi Feedback dari Mitra

\begin{tabular}{|l|l|l|l|l|}
\hline \multicolumn{1}{|c|}{$\begin{array}{c}\text { Butir-Butir Penilaian } \\
\text { (Feedback) }\end{array}$} & $\begin{array}{c}\text { Sangat } \\
\text { Tidak Setuju }\end{array}$ & $\begin{array}{c}\text { Tidak } \\
\text { Setuju }\end{array}$ & Setuju & \multicolumn{1}{|c|}{$\begin{array}{l}\text { Sangat } \\
\text { Setuju }\end{array}$} \\
\hline $\begin{array}{l}\text { Program pengabdian } \\
\text { masyarakat ini sudah sesuai } \\
\text { dengan tujuan kegiatan itu } \\
\text { sendiri. }\end{array}$ & $0 \%$ & $0 \%$ & $0 \%$ & $100 \%$ \\
\hline $\begin{array}{l}\text { Program pengabdian kepada } \\
\text { masyarakat ini sudah sesuai } \\
\text { dengan kebutuhan } \\
\text { masyarakat sasarnya. }\end{array}$ & $0 \%$ & $0 \%$ & $0 \%$ & $100 \%$ \\
\hline $\begin{array}{l}\text { Waktu pelaksanaan program } \\
\text { pengabdian masyarakat ini } \\
\text { relatif telah mencukupi } \\
\text { sesuai kebutuhan. }\end{array}$ & $0 \%$ & $20 \%$ & $50 \%$ & $30 \%$ \\
\hline $\begin{array}{l}\text { Dosen dan mahasiswa } \\
\text { Universitas Telkom bersikap } \\
\text { ramah, cepat dan tanggap } \\
\text { membantu selama kegiatan. }\end{array}$ & $0 \%$ & $0 \%$ & $0 \%$ & $100 \%$ \\
\hline
\end{tabular}




\begin{tabular}{|l|l|l|l|l|}
\hline \multicolumn{1}{|c|}{$\begin{array}{c}\text { Butir-Butir Penilaian } \\
\text { (Feedback) }\end{array}$} & $\begin{array}{c}\text { Sangat } \\
\text { Tidak Setuju }\end{array}$ & $\begin{array}{c}\text { Tidak } \\
\text { Setuju }\end{array}$ & Setuju & $\begin{array}{c}\text { Sangat } \\
\text { Setuju }\end{array}$ \\
\hline $\begin{array}{l}\text { Masyarakat setempat } \\
\text { menerima dan mengharapkan } \\
\text { program pengabdian } \\
\text { masyarakat Universitas } \\
\text { Telkom saat ini dan masa } \\
\text { yang akan } \\
\text { datang. }\end{array}$ & $0 \%$ & $0 \%$ & $0 \%$ & $100 \%$ \\
\hline
\end{tabular}

\section{Penutup}

Kegiatan ini disponsori oleh direktorat PPM Universitas Telkom dengan menggunakan skema kegaiatan pengabdian pada masyarakat internal regular. Program seperi ini sangat penting untuk terus di selenggarakan dan ditindak lanjuti menjadi program berkelanjutan disesuaikan dengan keperluan mitra akan bimbingan dari instutusi

\section{Daftar Pustaka}

Desperindag. (2018). Delapan Cara Jitu Mengembangkan UMKM (Usaha Mikro Kecil Menengah). Diambil kembali dari Https://disperindagkopukm. bangkatengahkab.go.id.

PPM. (t.thn.). Diambil kembali dari ppm Telkom university: https://ppm.telkomuniversity.ac.id

Pria Utama, H. e. (2016). Pembuatan Aplikasi Memantau Lokasi Anak Berbasis Android Menggunakan Location Based Service. Research Gate.

Sukapura, B. D. (2020). Profil BUMDES Desa Sukapura. Diambil kembali dari www. Sukapura.sideka.id

Sukapura, D. (2020). sukapura desa. Diambil kembali dari www.sukapura.desa.id 